\title{
Effects of Unidirectional In Situ Stress on Crack Propagation of a Jointed Rock Mass Subjected to Stress Wave
}

\author{
Zhanfeng Fan $\mathbb{D}^{1,2}$ and Jianhua Cai $\mathbb{1}^{3}$ \\ ${ }^{1}$ School of Architecture and Civil Engineering, Chengdu University, Chengdu 610106, China \\ ${ }^{2}$ School of Civil Engineering, Southwest Jiaotong University, Chengdu 610031, China \\ ${ }^{3}$ China Railway Southwest Research Institute Co., Ltd., Chengdu 611731, China \\ Correspondence should be addressed to Zhanfeng Fan; zhanfengfan@my.swjtu.edu.cn
}

Received 21 February 2021; Revised 27 July 2021; Accepted 13 August 2021; Published 30 August 2021

Academic Editor: Ahmed Ibrahim

Copyright (c) 2021 Zhanfeng Fan and Jianhua Cai. This is an open access article distributed under the Creative Commons Attribution License, which permits unrestricted use, distribution, and reproduction in any medium, provided the original work is properly cited.

\begin{abstract}
This paper proposes a large-scale experiment combined with multiple cement mortar blocks to simulate stress wave propagation across a jointed rock mass under unidirectional in situ stress. Two identical mortar block models with smooth, dry, and unfilled joints were poured. The stress waves in Model 1 and Model 2 were generated by an electric spark source and a blast-induced source, respectively. The effects of these two excitation sources on stress wave propagation were compared through crack propagation experiments. The experimental results show that the peak value of the transmitted strain wave decreases as the in situ stress increases. The unidirectional in situ stress has a certain inhibitory effect on the stress wave propagation. It also indicates that for Model 1 with the electric spark source, no cracks on the upper surface, but a Livingstone blasting crater at the bottom is generated. For Model 2 with the blast-induced source, cracks on the upper surface and a blasting crater at the bottom are produced. The results verify the similarity between the electric spark source and the explosive source. The two-dimensional finite element program (ANSYS/LS-DYNA) was applied to further simulate the crack propagation of a jointed rock mass under different in situ stresses. The results of numerical simulation verify that the in situ stress has a clear guiding effect on the crack propagation.
\end{abstract}

\section{Introduction}

In recent years, the rapid development of tunneling and hydropower engineering has greatly promoted tunnel excavations to deeper depth [1]. Through this work, high in situ stress has been identified as a characteristic property of deep jointed rock masses [2-4]. Therefore, the stress wave propagation in a jointed rock mass is significantly influenced not only by the joints but also by the in situ stress. In addition, the influence of in situ stress on the stability and failure of the surrounding rock mass at depth has become increasingly clear, improving the prediction of rockburst, large deformation, and complex tunnel geology. The behavior of rock masses is also governed by the in situ geological structure and stress conditions [5]. Consequently, the study of the stress wave propagation across jointed rock masses under in situ stress conditions has continued to attract considerable attention.

A considerable amount of literature has focused on the following two aspects of stress wave propagation through jointed rock masses: the properties of stress waves and the nature of joints. Research on the properties of stress waves includes the incident angles [6,7], the amplitude and frequency of incident waves [8], and different types of stress waves $[6,9]$. Researchers have also examined the nature of joints, including the joint closure constitutive relationship [10], the joint opening-closing behavior $[9,11]$, the number of joints [7, 12, 13], the joint stiffness [14], and the joint filling properties $[15,16]$, etc. Among them, most of these studies adopted small-scale laboratory experiments, i.e., SHPB (split Hopkinson pressure bar) experiments. In general, the diameter and length of the cylindrical sample of 
SHPB are $50 \mathrm{~mm}$ and $25 \mathrm{~mm}$, respectively. These experiments have significant side effects. Few studies have considered large-scale experiments under the coupling of in situ stress and dynamic stress loading.

The existing literature has indicated that in situ stress has strong effects on the failure strength and dynamic crack propagation of rock masses [17-19]. For instance, according to a biaxial compression test of a jointed rock mass with an opening, the propagation direction of the tensile cracks was found to be roughly normal to the joint surfaces [20]. High in situ stress was observed to resist the radially oriented pressure and damage extension around cut holes during tunneling excavation [21]. The levels and states of the in situ stress in the rock greatly affected the damage evolution, the crack initiation, and development and hence affected the fragmentation [22]. He et al. [23] have experimented with granite under several static and dynamic stresses to examine the crack propagation characteristics of blast-induced shock waves, and the results showed that the direction of the radial crack was related to the lateral pressure coefficient in the biaxial direction. The in situ stress could enhance the compression effect and weaken the tension effect in the radial direction of the borehole, and the jointed plane failure zone in coal masses decreased with increasing in situ stress [24]. Blasting of deeply buried structures is a complex dynamic process that can cause blast loading and in situ stress redistribution [25]. These studies mainly investigated the crack propagation of intact rock masses or rock masses containing microcracks or microvoids. The influence of the joints, large in extent and small in thickness compared with the wavelength of an incident wave, on crack propagation is rarely found in the available literature.

In addition to laboratory test methods, numerical simulation is an important method to investigate the blasting fracture mechanism. Currently, there are many numerical simulation methods, such as the finite element method (FEM), discrete element method (DEM), and boundary element method (BEM). Compared with the other two numerical methods mentioned above, FEM software ANSYS/LS-DYNA is advantageous in that the explicit dynamic analysis method can be used conveniently to simulate the large deformation of the material, and the explosives and other parameters can be input directly with a user subroutine interface. Since the FEM with a contact face can simulate crack growth in both the intact mass and the jointed plane, it may be a good method to study the fracture pattern in a jointed rock mass during the blasting process [26]. For example, the prediction of blast craters in brittle rock due to an underground explosion has been simulated using the LSDYNA based on the Taylor-Chen-Kuszmaul continuum damage model [27]. The Johnson-Holmquist material model was implemented in LS-DYNA through user subroutines to simulate the blasting-induced rock fractures [28]. A constitutive model considering dynamic compressive and tensile failure was applied to analyze crack initiation and propagation in coal masses using LS-DYNA [26]. The propagation characteristics of shock waves subjected to blasting load in a parallel jointed rock mass were investigated using LS-DYNA, and the results showed that the joint properties had a great effect on the propagation of blastinduced vibration [29]. In the present study, ANSYS/LSDYNA will be employed for crack propagation of a jointed rock mass under in situ stress.

As mentioned above, both the joints and the in situ stress influence the stress wave propagation across a jointed rock mass and consequently the crack propagation. Researchers have also realized the importance of these two factors in rock masses, but few have considered laboratory studies of wave propagation under unidirectional in situ stress. The theme of this study is to investigate crack propagation of a jointed rock mass caused by stress waves using two experimental models under unidirectional in situ stress. First, to simulate the joint distribution and apply different in situ stresses, a model consisting of multiple cement mortar blocks is presented. Then, we adopt a ZDF-3 (ZhiliuDian Fire-3) electric spark source to excite stress waves. This excitation source is compared with the blast-induced source through the law of crack propagation and the shape and size of the blasting crater in the model. Finally, the dynamic relaxation method of ANSYS/LS-DYNA is applied to study the law of crack propagation in jointed rock masses under unidirectional in situ stress. Our procedure provides a systematic methodology to quantify the crack propagation in a jointed rock mass under high in situ stress.

\section{Laboratory Experiment}

2.1. Experimental Model. A large-scale experimental model with multiple joints under unidirectional in situ stress was designed, as shown in Figure 1. The model materials mainly selected cement with a compressive strength of $30 \mathrm{MPa}$ and medium sand. The ratio of water, cement, and medium sand was $1: 4: 0.5$. The experiment did not consider the influence of the self-weight stress on stress wave propagation because the self-weight stress was very small compared to the in situ stress. Accordingly, it was not necessary to consider the weight similarity ratio of the model material.

The model was composed of a parent body and four jointed blocks. Hence, four parallel joints were formed into the model. A single joint was located on the left side of the parent body, and the remaining parallel joints were located on the right side. The experimental model mainly considered smooth, dry, and unfilled joints which mean no thickness joints. It is noted that the joints here are large in extent and small in thickness compared with the wavelength of an incident wave. The total size of the experimental model was $180 \mathrm{~cm} \times 80 \mathrm{~cm} \times 25 \mathrm{~cm}$ (length $\times$ width $\times$ height $)$ and much larger than the size of the sample of SHPB. Among them, the length, width, and height of the parent body were $80 \mathrm{~cm}$, $60 \mathrm{~cm}$, and $25 \mathrm{~cm}$, respectively, and the dimensions of the jointed block were the same as those of the parent body except that the width was $30 \mathrm{~cm}$, as shown in Figure 1(a). Two loads were applied along the length direction to simulate in situ stress. The other two directions had a free boundary. The size of the model is large enough to avoid the influence of reflected stress wave propagation [23, 30, 31]. Eight monitoring points were arranged sequentially from left to right, numbered $T 1$ to $T 8$, as shown in Figure 1(b). As 


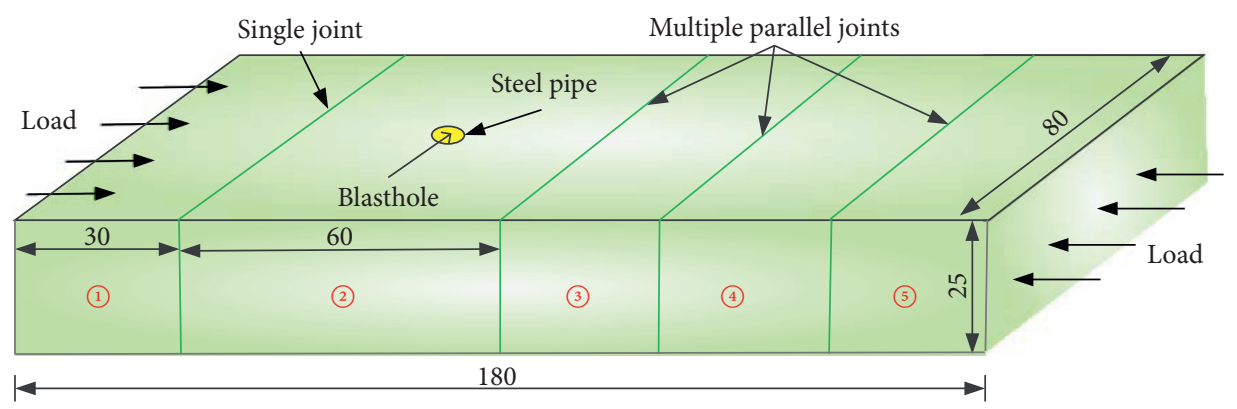

(a)
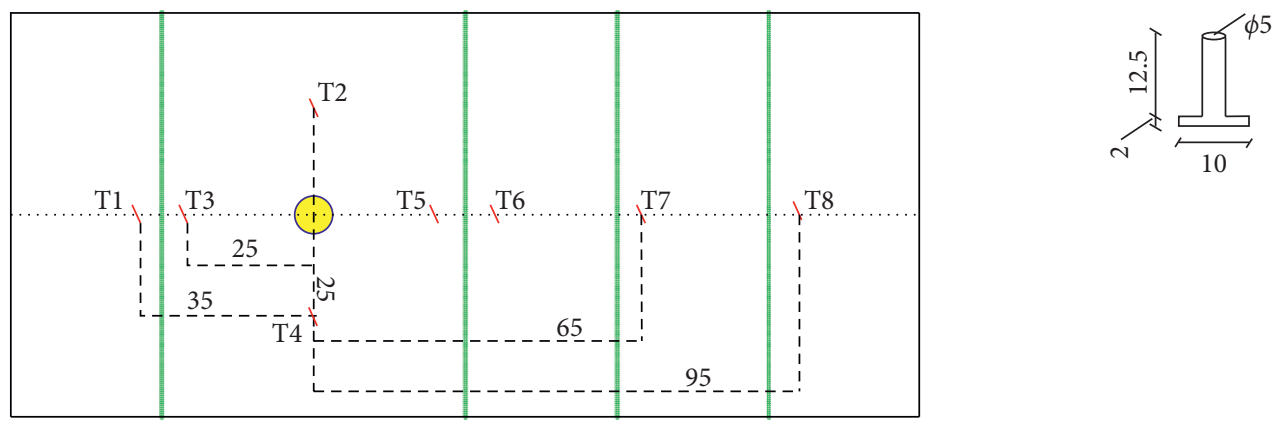

(b)

(c)

FIGURE 1: Schematic diagram of the model for stress waves propagating across jointed rock masses under unidirectional in situ stress (unit: $\mathrm{cm}$ ).

the distance of stress wave propagation increased, it was assumed that the stress wave measured at each pressure measurement point was a plane wave. To avoid the overflow of explosion gas from the bottom of the borehole during the experiment, a nonpenetrative blast hole was precut in the middle of the parent body and was surrounded by a cylindrical steel pipe with a base $(\phi 5 \mathrm{~cm} \times 12.5 \mathrm{~cm})$, as shown in Figure 1(c).

The poured and assembled model consisted of the unidirectional in situ stress loading device, the dynamic stress loading device, and the dynamic strain acquisition system, as shown in Figure 2. The physical and mechanical parameters of the cement mortar block are listed in Table 1, where $\rho_{c}$ denotes the density of the cement mortar block; $E_{c}$ and $\mu_{c}$ denote Young's modulus and Poisson's ratio, respectively; $\sigma_{c}, E_{\tan }$, and $v_{p}$ denote the uniaxial compressive strength, the tangent modulus, and the $P$ wave velocity, respectively.

2.2. ZDF-3 Electric Spark Source. Generally, the explosive is used as an excitation source in blasting tests. Once the explosive is detonated, the stress wave and explosion gas will coexist at the same time and are difficult to separate. Although explosive produces a wide frequency spectrum and a large amount of energy, it has poor controllability and is thus dangerous to work with. To study only the attenuation law of the stress wave, a new type of ZDF-3 (ZhiliuDian Fire-3) electric spark was selected as the excitation source, as shown in Figure 2(a).

The ZDF-3 electric spark source produces large energy and rich high-frequency components. The working principle of the ZDF-3 electric spark is to insert a special launch head into a blast hole filled with water, as shown in Figure 2(b), and then quickly charge the capacitor. Later, it uses ultrahigh voltage to instantly release energy into the water and thus generate stress waves. Compared with explosive detonation, its advantage is that only stress waves are produced without any explosion gas. The frequency range of the electric spark is $40 \mathrm{~Hz}$ to $300 \mathrm{~Hz}$. The spark energy can be expressed as follows [32]:

$$
Q=\frac{1}{2} C_{\text {cap }} U^{2}
$$

where $Q, C_{\text {cap }}(=420 \mu \mathrm{F})$, and $U$ are the emission energy, the capacitor capacitance, the voltage of the ZDF-3 electric spark, respectively. Due to the repeated application of dynamic loading to the model, a thick seamless steel pipe was embedded in the parent body of the model, as shown in Figure 2(c). The density of the seamless stainless steel pipe $\rho_{s}$ is $7900 \mathrm{~kg} / \mathrm{m}^{3}$, Young's modulus $E_{s}$ is $194.0 \mathrm{GPa}$, and Poisson's ratio $\mu_{s}$ is 0.25 , respectively. Meanwhile, eight steel bars were welded outside the stainless steel pipe to prevent it from separating from the cement mortar block.

2.3. Loading Equipment. An eight-channel ultradynamic data acquisition machine (DH5930) was used to collect dynamic strain measurements, as shown in Figure 2(d). The loading equipment was composed of two reaction frames, six steel strands, a ZB-500 electric fuel pump, and two center hole jacks, as shown in Figure 2(e)-2(g). The reaction frames were installed on the left and right sides of the model, and three steel strands were placed on the other sides. Uniform 


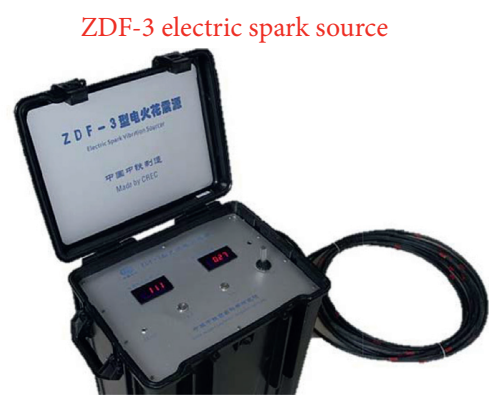

(a)

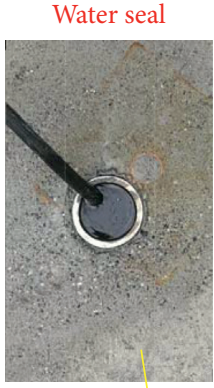

(b)

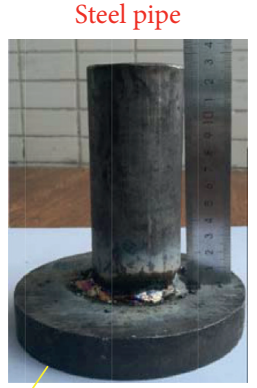

(c)
DH5939

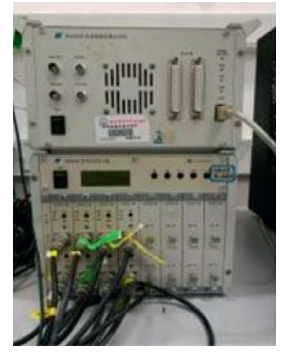

(d)

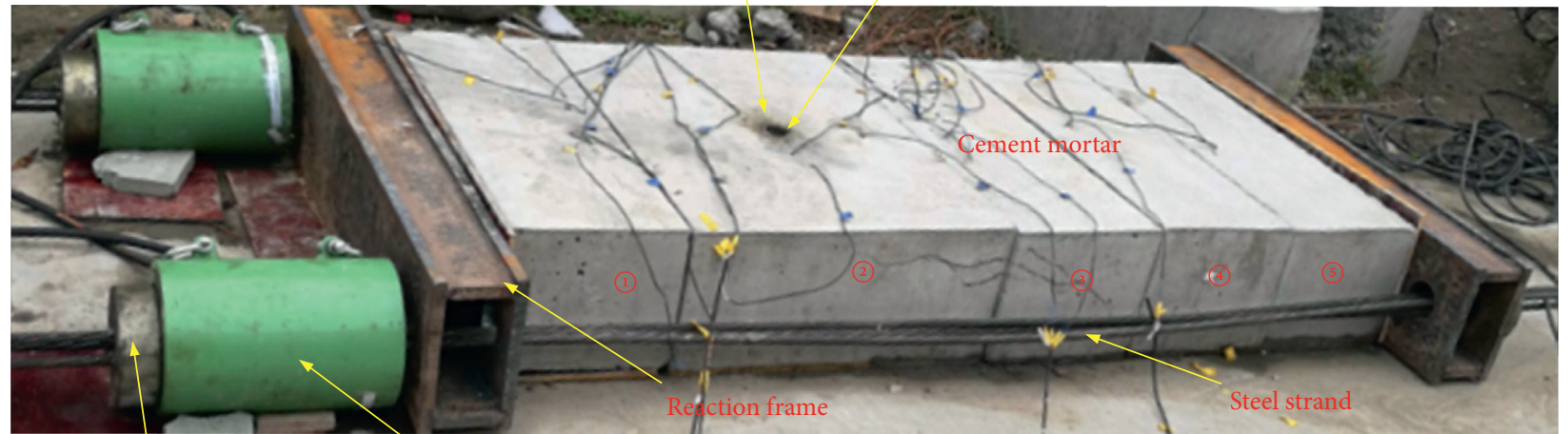

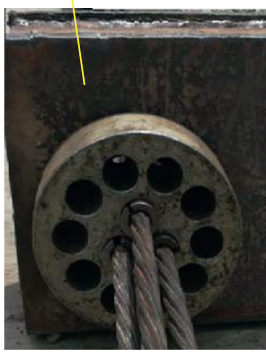

Prestressing anchorage

(e)

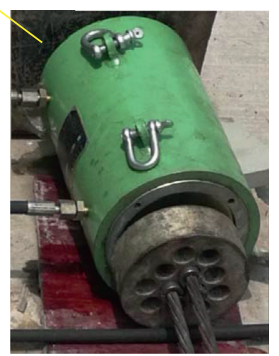

Center hole jack

(f)

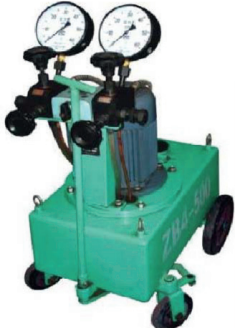

Electric fuel pump

(g)

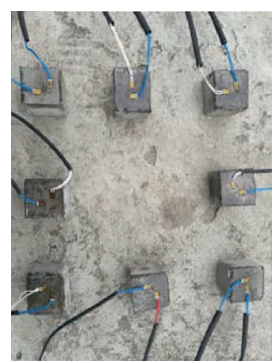

Strain brick

(h)

Figure 2: The model with cement mortar, including an in situ stress loading system and data acquisition system: (a) ZDF-3 electric spark source; (b) blast hole with water seal; (c) steel pipe; (d) eight-channel ultradynamic data acquisition machine (DH5930); (e) prestressing anchorage; (f) center hole jack; (g) ZB-500 electric fuel pump; (h) strain brick.

TABLE 1: The physical and mechanical parameters of cement mortar block.

\begin{tabular}{lccccc}
\hline$\rho_{c}\left(\mathrm{~kg} / \mathrm{m}^{3}\right)$ & $E_{c}(\mathrm{GPa})$ & $v$ & $\sigma_{c}(\mathrm{MPa})$ & $E_{\tan }(\mathrm{GPa})$ & $v_{p}(\mathrm{~m} / \mathrm{s})$ \\
\hline 2156 & 2.65 & 0.47 & 20 & 0.85 & 3227 \\
\hline
\end{tabular}

loads can be applied to the boundary of the model, and the maximum load was 5.0 MPa. To load the in situ stress, a ZB500 electric fuel pump was used to control two center hole jacks to tension the steel strand. Two strain gauges were pasted on each small strain brick embedded in the model shown in Figure 2(h).

2.4. Experimental Process. Uniform loads of the same magnitude were applied in one direction through the loading equipment including the static and dynamic stages. The static loading onto the cement mortar block was approximately symmetrically distributed, and the stress wave propagated evenly from the center blast hole of the parent body. Two identical mortar block models were poured. The experimental process of Model 1 was first implemented when using the ZDF-3 electric spark as the excitation source, as shown in Figure 3. The experimental process of Model 2 is the same as that of Model 1 except that blasting in the blast hole is used as the excitation source.

During the static stage, the in situ stress was loaded in one direction with the loading equipment. Six different magnitudes of the unidirectional in situ stress, including 0.5 $\mathrm{MPa}, 1.0 \mathrm{MPa}, 2.0 \mathrm{MPa}, 3.0 \mathrm{MPa}, 4.0 \mathrm{MPa}$, and $5.0 \mathrm{MPa}$, were considered. Each in situ stress loading was held for more than 10 minutes or until the cement mortar block was fully deformed.

During the dynamic stage, the blast hole was filled with water, and an electric spark cable with a copper core was inserted into the blast hole. The blast hole was blocked with plasticine and covered with an iron plate to seal the blast hole. Then, the ZDF-3 electric spark source was turned on 


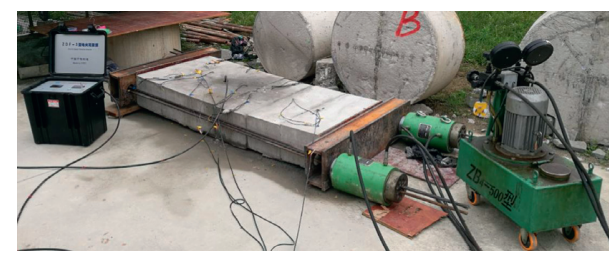

Figure 3: Model 1 field test using ZDF-3 electric spark source to generate stress waves.

and charged to the required voltage. Once the voltage was completely stable, it was suddenly released. At this point, the dynamic-static loading was complete. The dynamic strain curve of the measuring point was recorded through the DH5930 apparatus.

In the present study, three charging voltages were considered: $2500 \mathrm{~V}, 3000 \mathrm{~V}$, and $3500 \mathrm{~V}$. Each voltage was excited three times under each level of in situ stress, and thus 18 sets of dynamic strain data were obtained. Therefore, a total of 54 experiments were completed. When the electric spark was charged to $2500 \mathrm{~V}$, the emission energy was obtained in Table 2. The maximum and minimum average emission energies were $746.3 \mathrm{~J}$ and $665.5 \mathrm{~J}$, respectively. Overall, the electric spark excitation energy is adjustable and controllable. It is feasible to use the ZDF-3 electric spark source to replace the blast-induced source with exciting stress waves.

\section{Results and Discussion}

In this section, the dynamic strains of monitoring points $\mathrm{T} 1$ and T8 in Model 1 using the ZDF-3 electric spark source are presented. After that, the crack propagation patterns of the parent bodies of Model 1 using the ZDF-3 electric spark source and Model 2 using the blast-induced source are analyzed.

3.1. Dynamic Strain. Figure 4 shows the waveforms of the transmitted strain wave at $T 1$ under unidirectional in situ stress when the stress wave passes through a single joint, where the symbol "_" indicates compression and "+" indicates tension. The charging voltage is $2500 \mathrm{~V}$. Regardless of the in situ stress, the transmitted strain wave first exhibits a compressive wave and then a reflected tensile wave. When the in situ stress varies from $0.5 \mathrm{MPa}$ to $5.0 \mathrm{MPa}$, the peak value of the transmitted strain wave decreases from $9.4 E 4 \mu \varepsilon$ to $5.28 E 4 \mu \varepsilon$, and the time interval required to reach the peak of the transmitted strain wave is $217.1 \mu \mathrm{s}, 221.3 \mu \mathrm{s}, 216.4 \mu \mathrm{s}$, $213.5 \mu \mathrm{s}, 211.6 \mu \mathrm{s}, 193.1 \mu \mathrm{s}$, respectively. The greater the in situ stress is, the smaller the dynamic deformation of the rock mass caused by the stress wave. Therefore, the in situ stress has a certain inhibitory effect on stress wave propagation when the initial in situ stress and the stress waves are superimposed. Although the increasing in situ stress will lead to the closure of the joint to a certain extent, the jointed rock mass may produce new microcracks and plastic deformation under the combined action of dynamic and static stress.
Figure 5 shows the waveforms of the transmitted strain wave at $T 8$ under different in situ stresses when the stress wave passes through multiple parallel joints. The attenuation law of the transmitted strain wave of the three joints is similar to that of the single joint; that is, the compressive wave appears first, and then the tensile wave appears. There are subsequent peaks after the first peak. The peak value of the transmitted strain wave decreases from $2.46 E 4 \mu \varepsilon$ to $1.2 E 4 \mu \varepsilon$ when the in situ stress gradually increases from $0.5 \mathrm{MPa}$ to $5.0 \mathrm{MPa}$. The results show that the unidirectional in situ stress has a great influence on the stress wave propagation and attenuation. When the in situ stress is the same, the dynamic strain of $T 8$ is significantly less than that of $T 1$ because of the increase in the number of joints.

3.2. Crack Propagation of Model 1. The crack distribution patterns on the upper and bottom surfaces of the parent body of Model 1 are shown in Figure 6. No cracks are observed on the upper surface of Model 1, as shown in Figure 6(a). However, radial cracks and circumferential cracks appear on the lower surface of the matrix along the center of the model, as shown in Figure 6(b). Additionally, a Livingstone blasting crater formed during the experiment, and the funnel body is completely separated from the parent body. The diameter of the crater is approximately $52 \mathrm{~cm}$, and the depth is $10 \mathrm{~cm}$. The results of Model 1 show that a single stress wave loading may not be enough to cause damage to the jointed rock mass, but the repeated stress waves loading can cause the jointed rock mass instability and failure.

3.3. Crack Propagation of Model 2. Model 2 was blasted nine times, and the detonator was buried $12.5 \mathrm{~cm}$ deep. Most blast-induced sources used a delay detonator and water as the coupling medium, except for the second blast, which used a detonator and $4.9 \mathrm{~g}$ of explosives and blocked the blast hole with mud. The in situ stress loading increased from $0.5 \mathrm{MPa}$ to $5.0 \mathrm{MPa}$. The specific cases and the parameters of filling delay detonator and explosive in Model 2 are listed in Table 3. The evolution of the crack distribution in the parent body of Model 2 from the first to ninth blast is shown in Figure 7. The following test results were observed:

(1) No cracks were observed around the blast hole after blasting when the in situ stress loading was $0.5 \mathrm{MPa}$ and $1.0 \mathrm{MPa}$, respectively. An initially very small crack around the blast hole had appeared since the 3rd blasting when the in situ stress was $2.0 \mathrm{MPa}$. After the 5th blasting, the crack tended to propagate along the loading direction when the in situ stress reached 3.0 $\mathrm{MPa}$. This phenomenon indicates that the initial in situ stress can affect crack propagation. A superposition effect occurs if the stress wave encounters the in situ stress. Other researchers have reported similar conclusions. For example, Nicholls and Duvall [33] pointed out that the presplitting of test specimens along with the maximum in situ stress under confining pressure much more easily passed field tests than presplitting in other directions. Simha 
TABle 2: Emission energy of ZDF-3 electric spark (2500 V).

\begin{tabular}{|c|c|c|c|c|c|c|}
\hline $\begin{array}{l}\text { In situ stress } \\
(\mathrm{MPa})\end{array}$ & Number & $\begin{array}{l}\text { Charging voltage } \\
\text { (V) }\end{array}$ & $\begin{array}{l}\text { Residual voltage } \\
(\mathrm{V})\end{array}$ & $\begin{array}{l}\text { Actual voltage } \\
(\mathrm{V})\end{array}$ & $\begin{array}{c}\text { Emission energy } \\
(\mathrm{J})\end{array}$ & $\begin{array}{c}\text { Average emission energy } \\
(\mathrm{J})\end{array}$ \\
\hline 0.5 & 1 & 2500 & 640 & 1860 & 726.5 & \\
\hline 0.5 & 2 & 2500 & 650 & 1850 & 718.7 & 734.4 \\
\hline 0.5 & 3 & 2500 & 600 & 1900 & 758.1 & \\
\hline 1.0 & 1 & 2500 & 600 & 1900 & 758.1 & \\
\hline 1.0 & 2 & 2500 & 600 & 1900 & 758.1 & 745.0 \\
\hline 1.0 & 3 & 2500 & 650 & 1850 & 742.2 & \\
\hline 2.0 & 1 & 2500 & 620 & 1880 & 742.2 & \\
\hline 2.0 & 2 & 2500 & 650 & 1850 & 718.7 & 742.4 \\
\hline 2.0 & 3 & 2500 & 590 & 1910 & 766.1 & \\
\hline 3.0 & 1 & 2500 & 640 & 1860 & 726.5 & \\
\hline 3.0 & 2 & 2500 & 1 & I & I & 746.3 \\
\hline 3.0 & 3 & 2500 & 590 & 1910 & 766.1 & \\
\hline 4.0 & 1 & 2500 & 710 & 1790 & 672.9 & \\
\hline 4.0 & 2 & 2500 & 700 & 1800 & 680.4 & 665.5 \\
\hline 4.0 & 3 & 2500 & 750 & 1750 & 643.1 & \\
\hline 5.0 & 1 & 2500 & 700 & 1800 & 680.4 & \\
\hline 5.0 & 2 & 2500 & 620 & 1880 & 742.2 & 719.0 \\
\hline 5.0 & 3 & 2500 & 630 & 1870 & 734.3 & \\
\hline
\end{tabular}

Note: "l" indicates that no data has been collected.

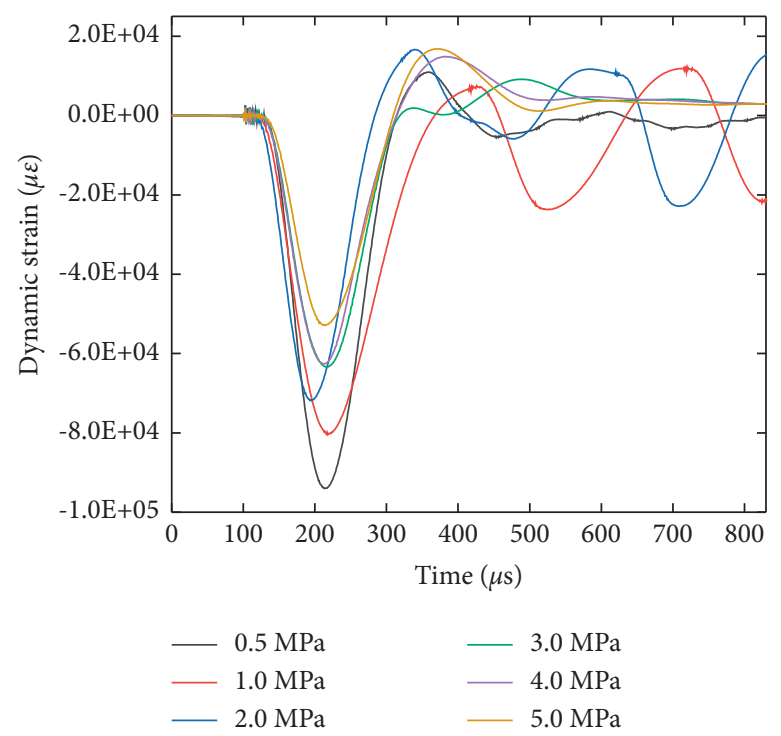

Figure 4: The dynamic strain curve of $T 1$ in Model 1 versus time.

and Fourney [34] proposed the static stress field to blast fracture mode of testing and concluded that the preferred fracturing direction of polymethyl methacrylate (PMMA) was the direction of maximum principal stress.

(2) The propagation direction of the cracks around the blast hole was not completely parallel to the loading direction but was at an angle to the loading direction. This phenomenon occurred after the 3rd blast, and the cracks became longer and wider with increasing in situ stress, as shown in Figure 7. For the so-called inclined deflection cracks, the angle between the crack and the in situ stress was between $15^{\circ}$ and $45^{\circ}$.
In other words, the crack propagation direction intersected the in situ stress loading direction.

(3) From the first blast to the end of the experiment, no cracks were observed perpendicular to the loading direction. Due to the steel pipe surrounding the blast hole, the annular crack around the blast hole was very small, and the steel pipe also blocked the explosion gas from wedging into the cement mortar block. The extent of the blasting damage zone around the blast hole decreased as the in situ stress increased.

(4) After nine blasts, an irregular circular area of deformation appeared at the bottom of Model 2, as shown in Figure 8. The diameter of the profile of the 


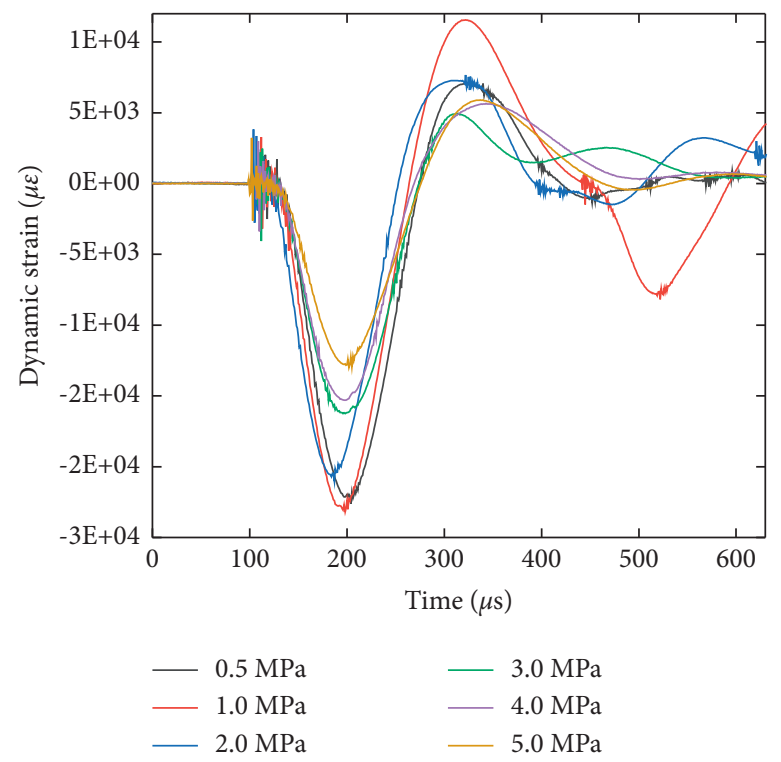

Figure 5: The dynamic strain curve of $T 8$ in Model 1 versus time.

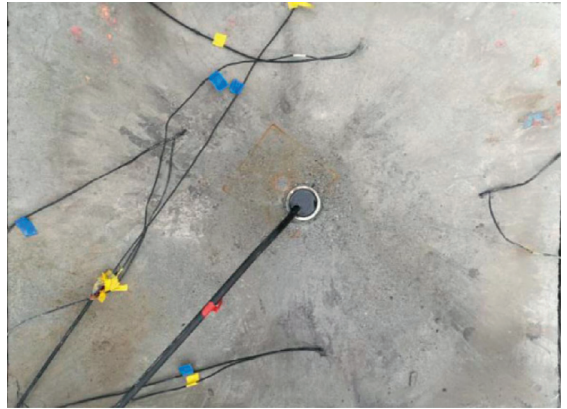

(a)

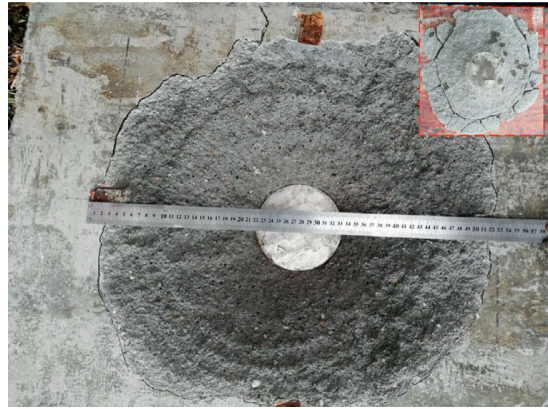

(b)

Figure 6: The crack distribution patterns of the parent body of Model 1 using the ZDF-3 electric spark. (a) No cracks visible on the top surface of the parent body. (b) A Livingston blast crater with a diameter of approximately $52 \mathrm{~cm}$ and a depth of $10 \mathrm{~cm}$ at the bottom of the parent body.

Table 3: Parameters of filling delay detonator and explosive in Model 2.

\begin{tabular}{lccc}
\hline In situ stress $(\mathrm{MPa})$ & Explosive charge & Stemming & Number of blasts \\
\hline 0.5 & 1 delay detonator & Water & 1 \\
1.0 & 1 delay detonator and $4.9 \mathrm{~g}$ explosives & Mud & 1 \\
2.0 & 1 delay detonator & Water & 1 \\
3.0 & 1 delay detonator & Water & 2 \\
4.0 & 1 delay detonator & Water & 2 \\
5.0 & 1 delay detonator & Water & 2 \\
\hline
\end{tabular}

blasting crater was approximately $30 \mathrm{~cm}$. This crack connected with the upper surface crack on the side of Model 2 (the yellow dotted line). However, the funnel body did not fall off.

The above results show that the in situ stress state of the rock mass greatly affects the damage evolution and crack initiation and development and therefore affects fragmentation [22]. The damage development tends towards the direction at which the unidirectional in situ stress is applied. In addition, the crack propagation patterns of Model 1 and Model 2 verify the similarity between the ZDF-3 electric spark source and the blast-induced source. Although the energy of the ZDF-3 electric spark is not as large as that of the explosive, it can play an important role in stress wave propagation and can be used as an excitation source in stress wave propagation.

\section{Numerical Simulation of Crack Propagation}

Since it is difficult to obtain an analytical solution for nonelastic materials under blasting, there has been a considerable amount of researches on the numerical simulation 


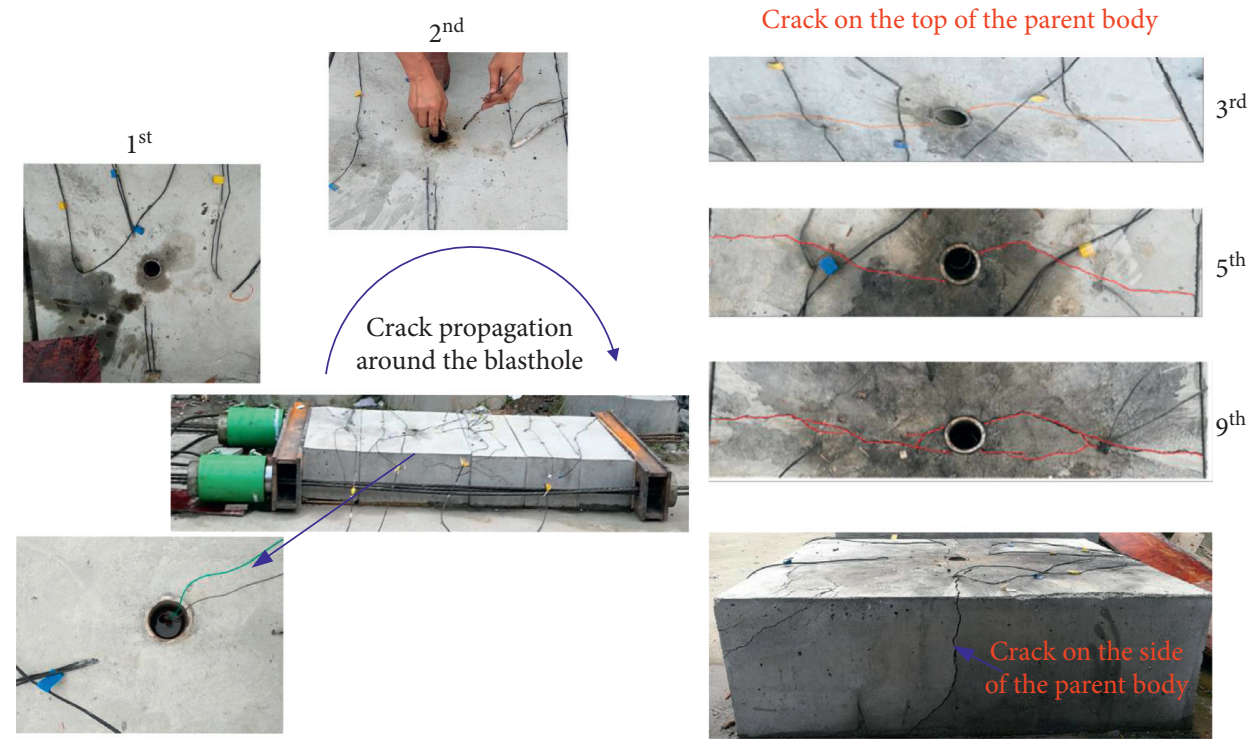

FIGURE 7: Crack propagation around the blast hole on the top and side of the parent body in Model 2 after nine blasts with a delay detonator and explosive.

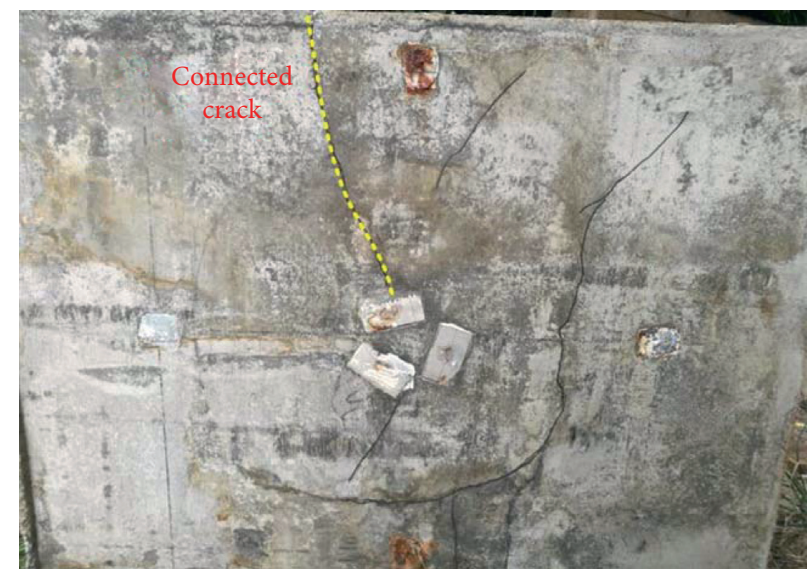

FIgURe 8: A blasting crater at the bottom of the parent body in Model 2.

of blasting funnels $[21,27,35,36]$. To further confirm that the blasting cracks in the jointed rock mass propagate along the loading direction under dynamic and static loading, a numerical simulation to take into account the nonlinear response of jointed rock masses is conducted in this research. A plane strain numerical calculation model is established using the finite element program ANSYS/LSDYNA. The calculation model is the same size as the parent body of the models described in Section 2. Only unidirectional in situ stress (denoted as $P 1$ ) is considered in the calculation, as shown in Figure 9.

When the explosive is detonated, the strain of the rock mass near the charge is very large, and the strain rate effect is obvious. Therefore, the Cowper-Symonds model is considered. The elastic-plastic-kinematic model considers the effect of strain rate and strain hardening on the rock mass and can accurately describe the fracture pattern during blasting [37-39]. The expression is written as follows [40]:

$$
\left\{\begin{array}{l}
\sigma_{y}=\left[1+\left(\frac{\dot{\varepsilon}}{C}\right)^{1 / P}\right]\left(\sigma_{0}+\beta E_{p} \varepsilon_{p}^{e f f}\right), \\
E_{p}=\frac{E_{c} E_{\tan }}{E_{c}-E_{\tan }},
\end{array}\right.
$$

where $E_{c}$, and $E_{\tan }$ are the same as before, $\sigma_{0}$ is the initial stress, $\sigma_{y}$ is the failure stress, $\dot{\varepsilon}$ is the strain rate, $E_{p}$ is the plastic hardening modulus, $\beta$ is the hardening parameter $(0<\beta<1)$, and $C$ and $P$ are Cowper-Symonds strain rate parameter, respectively. The effective plastic strain $\varepsilon_{p}^{\text {eff }}$ can be calculated as follows:

$$
\left\{\begin{array}{l}
\varepsilon_{p}^{\text {eff }}=\int_{0}^{t_{a}} d \varepsilon_{p}^{\text {eff }}, \\
d \varepsilon_{p}^{\text {eff }}=\sqrt{\frac{2}{3} d \varepsilon_{i j}^{p} d \varepsilon_{i j}^{p}},
\end{array}\right.
$$




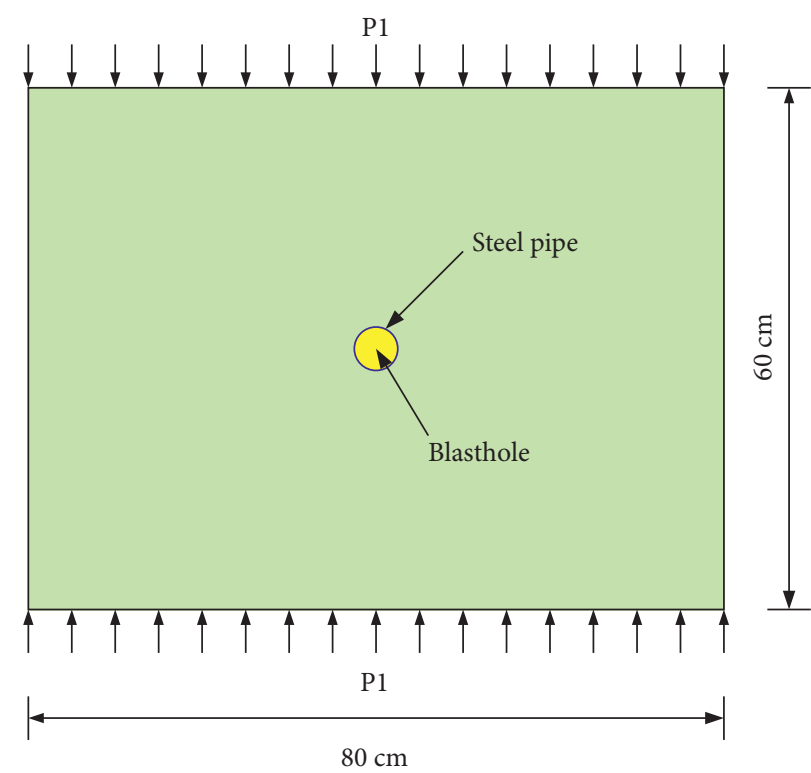

Figure 9: The numerical model of dynamic and static coupling of the parent body.

where $\varepsilon_{p}^{\text {eff }}$ is the effective plastic strain, $t_{a}$ is the cumulative time of plastic strain, and $\varepsilon_{i j}^{p}$ is the partial component of plastic deviation strain of the rock mass. In this simulation, $C=2.63 ; P=3.69 ; \beta=0.15 ; \varepsilon_{p}^{\text {eff }}=1.25$.

In LS-DYNA, the Jones-Wilkens-Lee (JWL) equation of state is used to describe the chemical reactions after explosive detonation [40]. The JWL equation of state defines the pressure as follows:

$$
p_{b}=A\left(1-\frac{\omega}{R_{1} V}\right) e^{-R_{1} V}+B\left(1-\frac{\omega}{R_{2} V}\right) e^{-R_{2} V}+\frac{\omega E}{V},
$$

and is usually used for detonation products of high explosives, where $p_{b}$ is the pressure of the detonation products. $V$ is the relative specific volume of the detonation products. $E$ is the specific internal energy of the detonation products. $A, B, R_{1}, R_{2}$, and $\omega$ are parameters of JWL equation of state, respectively. In this study, the parameters of the JWL equation of state are listed in Table 4, where $\rho_{e}$ is the explosive density, $P_{C J}$ is the Chapman-Jouguet pressure, and $\mathrm{VoD}$ is the velocity of detonation.

Four cases are considered: (i) Case I: $P 1=0 \mathrm{MPa}$, and a steel pipe is either included or excluded in the model; (ii) Case II: $P 1=0.5 \mathrm{MPa}$, and a steel pipe is included; (iii) Case III: $P 1=1.0 \mathrm{MPa}$, and a steel pipe is included; (iv) Case IV: $P 1=2.0 \mathrm{MPa}$, and a steel pipe is included. The parameters of the numerical calculation model are listed in Table 1. The SOLID185 with eight nodes of hexahedral element is adopted. Only two elements are set in the thickness direction due to the plane strain assumption. The numerical simulations have a total of 64250 elements. In the finite element method, the joint is usually treated as a boundary. The boundary conditions were specified as follows: the upper and lower sides are nonreflecting boundaries, while the other two sides are free faces. The numerical simulation adopts the $\mathrm{cm}$ g- $\mu$ s unit system.
4.1. Case I. Case I mainly compares the damage zones around the blast hole with and without a steel pipe. In this case, only the dynamic calculation steps of ANSYS/LSDYNA are required due to the lack of in situ stress. The blast hole without a steel pipe is completely destroyed, and a crushing area is formed, as shown in Figure 10(a). The symmetrical cracks are distributed at the periphery of the crushing zone. The distribution of the damage zone around the blast hole with a steel pipe is shown in Figure 10(b). Compared with that in Figure 10(a), the range of the damage zone in Figure 10(b) is significantly reduced. Only small cracks around the steel pipe are observed, and the steel pipe separates from the parent body. The maximum dynamic strain is $1.87 E 4 \mu \varepsilon$. These findings explain why eight steel bars should be welded outside the stainless steel pipe in the model. The explosion gas does not wedge into the cement mortar block after the explosive is detonated, further confirming that the stress wave can damage the rock mass.

4.2. Case II. In Case II, the unidirectional in situ stress is loaded first, and then a dynamic loading is applied on the blast hole. The dynamic relaxation method of the ANSYS/ LS-DYNA is used to obtain the nodal stress and displacement of each element under the initial in situ stress before and after blasting $[24,41,42]$. The distribution of the stress and the damage zone around the blast hole with unidirectional in situ stress $(P 1=0.5 \mathrm{MPa})$ is shown in Figure 11. At the static loading stage, the distribution of the maximum tensile and compressive stress is shown in Figure 11(a). The upper and lower sides of the rock mass are compressed, and the left and right sides are subjected to tension only when unidirectional in situ stress is applied. At the dynamic loading stage, the stress of each element obtained from the static analysis is input into the initial stress of the dynamic analysis, and then the explosion analysis is performed. Very 
TABLE 4: Parameters of emulsion explosive and JWL equation of state.

\begin{tabular}{lcccccccc}
\hline$\rho_{e}\left(\mathrm{~kg} / \mathrm{m}^{3}\right)$ & $\mathrm{VoD}(\mathrm{m} / \mathrm{s})$ & $p_{C J}(\mathrm{GPa})$ & $A(\mathrm{GPa})$ & $B(\mathrm{GPa})$ & $R_{1}$ & $R_{2}$ & $\omega$ & $E(\mathrm{GPa})$ \\
\hline 1300 & 4000 & 0.27 & 214.4 & 0.182 & 4.2 & 0.9 & 0.15 & 4 \\
\hline
\end{tabular}

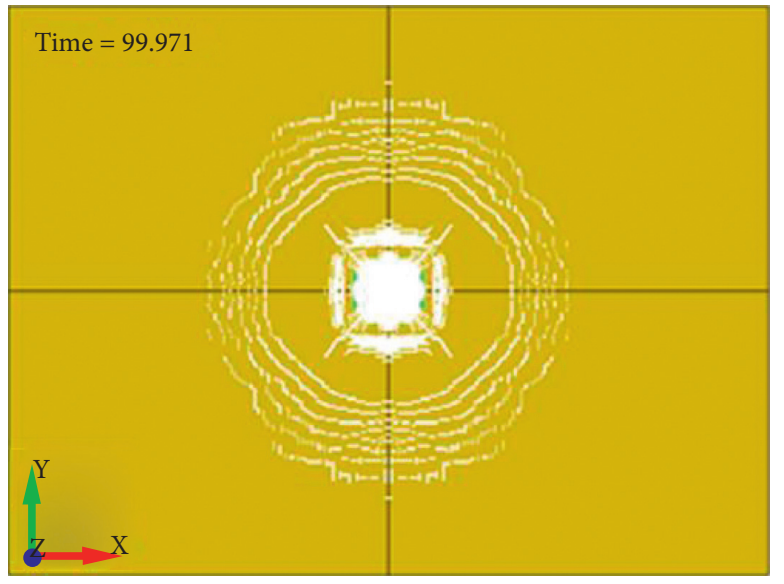

(a)

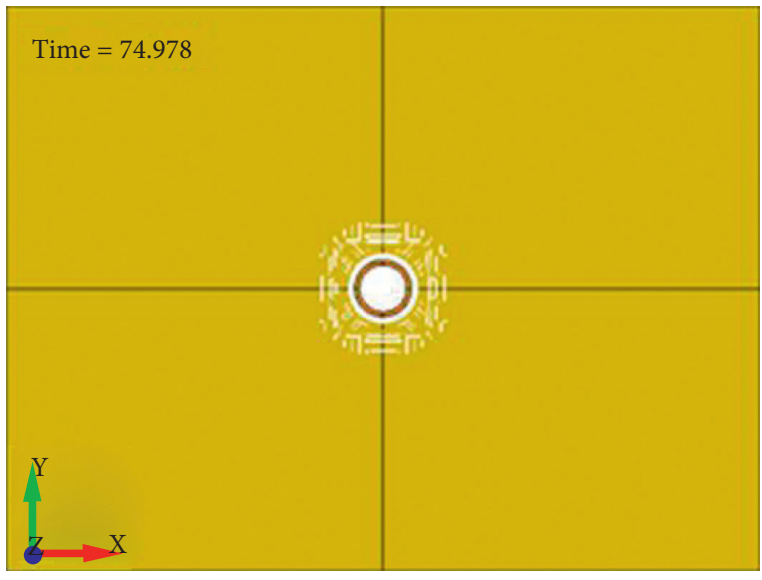

(b)

Figure 10: Distribution of damage zone around blast holes with and without a steel pipe (Case I P1 = $0 \mathrm{MPa}$ ). (a) Damage zone around the blast hole without steel pipe. (b) Damage zone around the blast hole with a steel pipe.

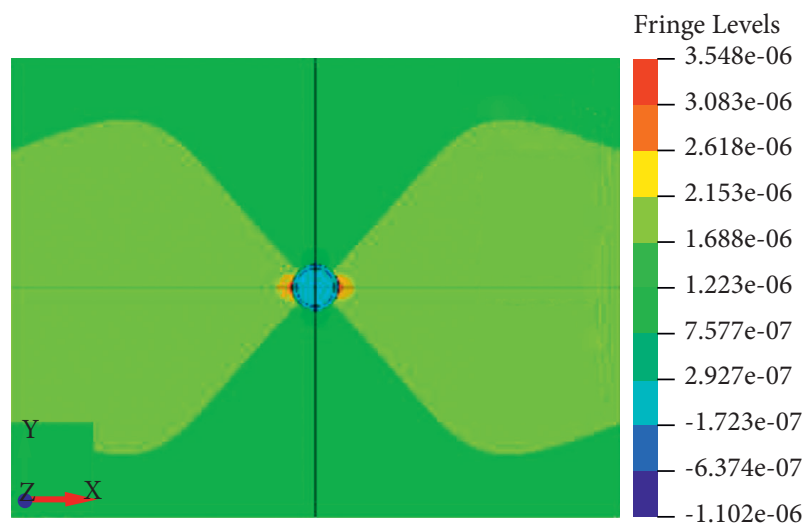

(a)

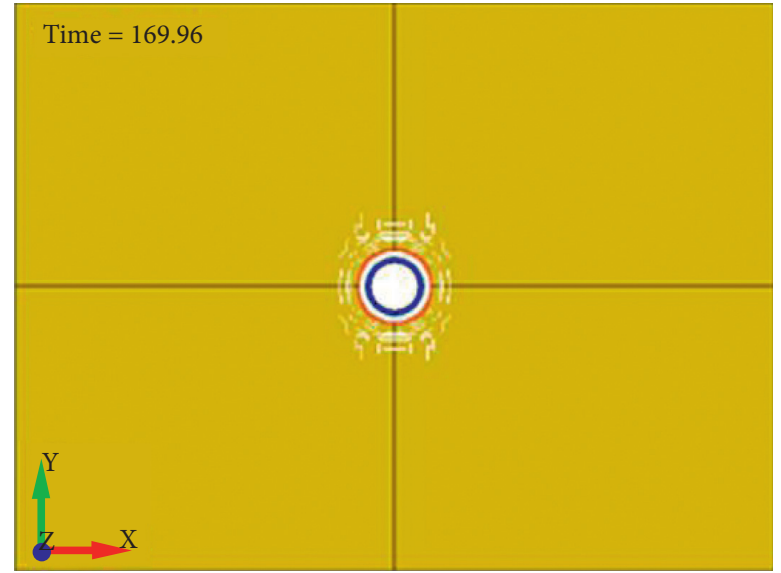

(b)

Figure 11: The stress distribution and damage zone around a blast hole under unidirectional in situ stress (Case II: $P 1=0.5 \mathrm{MPa}$ ). (a) Distribution of tensile and compressive stress. (b) Damage zone around a blast hole.

small cracks form around the blast hole, as shown in Figure 11(b). The maximum dynamic strain is $3.34 E 4 \mu \varepsilon$. The range of crack propagation is small because the applied unidirectional in situ stress is low.

4.3. Case III. At the static stage, the maximum tensile and compressive stress under the action of the static stress field in the rock mass tends to increase when the unidirectional in situ stress increases to 1.0 MPa, as shown in Figure 12(a). After approximately $234.96 \mu$ s of dynamic loading, the distribution of the damage zone around the blast hole is shown in Figure 12(b). The maximum dynamic strain is $6.68 E 4 \mu \varepsilon$. Two distinctly continuous cracks appear along the loading direction and then extend to the boundary. It is shown that the in situ stress has a clear guiding effect on the stress wave propagation. The crack propagation perpendicular to the direction of the unidirectional in situ stress is not obvious. These results are consistent with the crack propagation of Model 2 in Section 3. The difference between the two is that the crack propagation direction observed in Model 2 is at an angle to the loading direction, but the two 


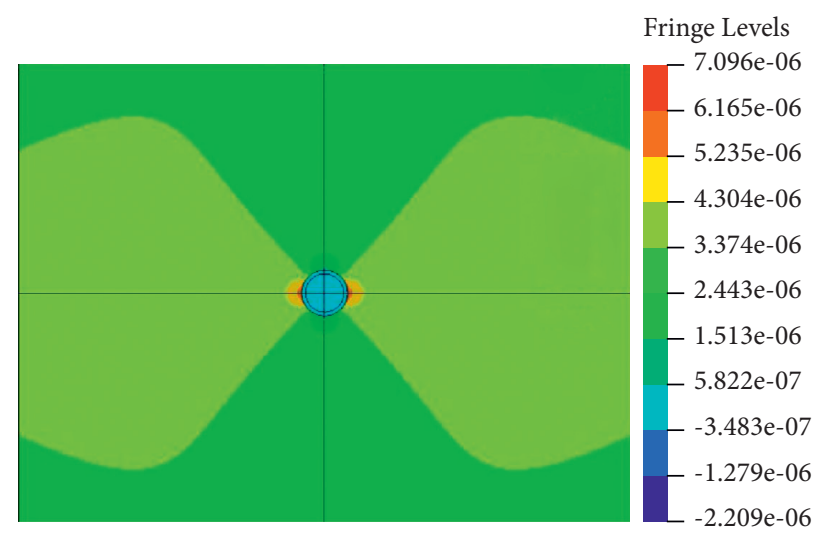

(a)

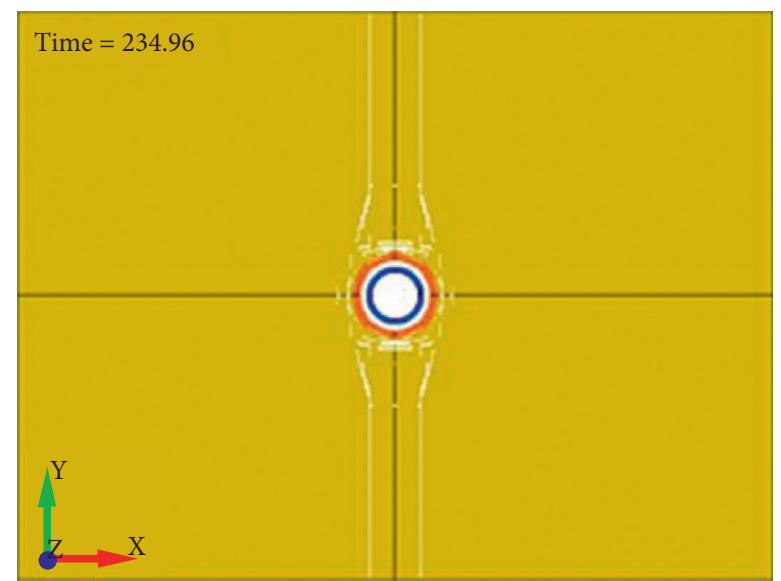

(b)

FIgURE 12: The distribution of stress and crack propagation around a blast hole under unidirectional in situ stress (Case III: $P=1.0 \mathrm{MPa}$ ). (a) Distribution of tensile and compressive stress. (b) Crack propagation along the loading direction.

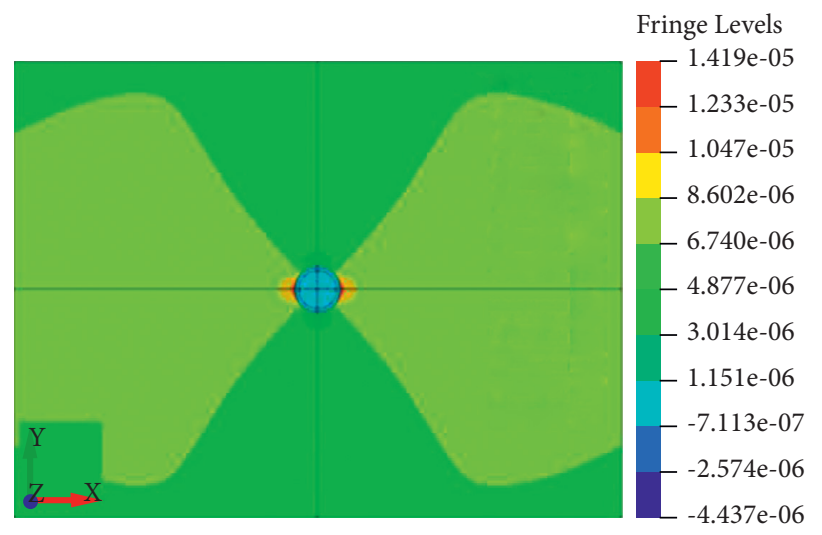

(a)

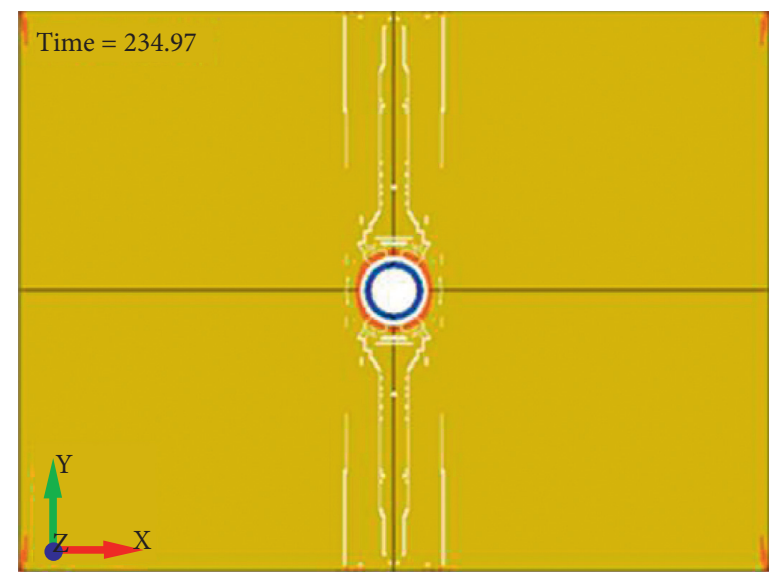

(b)

Figure 13: The distribution of stress and crack propagation around a blast hole under unidirectional in situ stress (Case IV: $P 1=2.0 \mathrm{MPa})$. (a) Distribution of tensile and compressive stress. (b) Two reflective tensile cracks.

cracks in the numerical calculation are parallel to the loading direction. The reason for this discrepancy may be related to the presence of microcracks and the plane strain assumption.

4.4. Case IV. The maximum tensile and compressive stress increase, and the cracks propagate farther when the unidirectional in situ stress is continuously increased to 2.0 $\mathrm{MPa}$, as shown in Figure 13. The maximum dynamic strain is $9.38 E 4 \mu \varepsilon$. In addition to the crack observed in Case III, two reflective tensile cracks form along the direction of the unidirectional in situ stress loading. The reason for this phenomenon may be that the nonreflecting boundaries cannot completely absorb the reflected waves. The crack is still not observed in the vertical direction of in situ stress loading, further verifying that the in situ stress has a guiding effect on crack propagation. Xie et al. [21] indicate that the initial in situ stress has the effect of increasing the tensile stress and reducing the compressive stress; that is, the initial in situ stress has the effect of inhibiting the development of radial cracks.

\section{Conclusions}

This paper examines the stress wave propagation through a single joint and multiple parallel joints under unidirectional in situ stress by laboratory experiments and numerical simulations. The crack propagation of the ZDF-3 electric spark source and blast-induced source in the jointed rock mass are compared. Key findings are summarized below:

(1) We investigate the propagation and attenuation characteristics of stress wave, which are generated by a ZDF-3 electric spark on the larger-scale model with multiple cement mortar blocks. The attenuation laws of the transmitted strain wave are similar for a single joint and multiple parallel joints. The peak value of the dynamic strain decreases as the in situ stress 
increases. Due to the increase of joint number, the dynamic strain of rock mass with multiple parallel joints is significantly less than that with a single joint. The in situ stress has a certain inhibitory effect on the stress wave propagation.

(2) The crack propagation experiments in jointed rock masses under unidirectional in situ stress demonstrate the similarity between the ZDF-3 electric spark source and the blast-induced source. Whether the ZDF-3 electric spark excitation or the explosive excitation is used, a blasting crater appears at the bottom of the model. The blasting funnel body separates from the parent body in Model 1 but does not separate in Model 2. The ZDF-3 electric spark can be used as an excitation source in stress wave propagation. The in situ stress has a guiding effect on crack propagation, and an inclined deflection crack is formed on the upper surface of Model 2.

(3) The crack propagation in the parent body of Model 2 is analyzed using the dynamic relaxation method of ANSYS/LS-DYNA. The numerical simulation results show that two parallel cracks are generated along the direction of the in situ stress loading, which is consistent with the phenomenon observed in the laboratory experiment. The numerical simulation further verifies that the in situ stress has a guiding effect on the crack propagation.

\section{Data Availability}

No data were used to support this study.

\section{Conflicts of Interest}

The authors declare no conflicts of interest.

\section{References}

[1] X. Li, C. Li, W. Cao, and M. Tao, "Dynamic stress concentration and energy evolution of deep-buried tunnels under blasting loads," International Journal of Rock Mechanics and Mining Sciences, vol. 104, pp. 131-146, 2018.

[2] M. He, "Latest progress of soft rock mechanics and engineering in China," Journal of Rock Mechanics and Geotechnical Engineering, vol. 6, no. 3, pp. 165-179, 2014.

[3] T. Yin, L. Bai, X. Li, X. Li, and S. Zhang, "Effect of thermal treatment on the mode I fracture toughness of granite under dynamic and static coupling load," Engineering Fracture Mechanics, vol. 199, pp. 143-158, 2018.

[4] W. Liang, G. Zhao, H. Wu, and B. Dai, "Risk assessment of rockburst via an extended MABAC method under fuzzy environment," Tunnelling and Underground Space Technology, vol. 83, pp. 533-544, 2019.

[5] D. Huang, J. Wang, and S. Liu, "A comprehensive study on the smooth joint model in DEM simulation of jointed rock masses," Granular Matter, vol. 17, no. 6, pp. 775-791, 2015.

[6] J. C. Li, H. B. Li, G. W. Ma, and J. Zhao, "A time-domain recursive method to analyse transient wave propagation across rock joints," Geophysical Journal International, vol. 188, no. 2, pp. 631-644, 2012.
[7] J. B. Zhu and J. Zhao, "Obliquely incident wave propagation across rock joints with virtual wave source method," Journal of Applied Geophysics, vol. 88, pp. 23-30, 2013.

[8] L. F. Fan and H. Y. Sun, "Seismic wave propagation through an in-situ stressed rock mass," Journal of Applied Geophysics, vol. 121, pp. 13-20, 2015.

[9] W. Wang, H. Hao, X. Li, Z. Yan, and F. Gong, "Effects of a single open joint on energy transmission coefficients of stress waves with different waveforms," Rock Mechanics and Rock Engineering, vol. 48, no. 5, pp. 2157-2166, 2015.

[10] J. Zhao and J. G. Cai, "Transmission of elastic p-waves across single fractures with a nonlinear normal deformational behavior," Rock Mechanics and Rock Engineering, vol. 34, no. 1, pp. 3-22, 2001.

[11] H. Li, Y. Liu, J. Li et al., "Numerical study on oblique incidence across rock masses with linear and nonlinear joints," Arabian Journal of Geosciences, vol. 9, no. 1, p. 20, 2016.

[12] X. L. Huang, S. W. Qi, Y. S. Liu, and Z. F. Zhan, "Stress wave propagation through viscous-elastic jointed rock masses using propagator matrix method (PMM), geophys," Journal of Intelligence, vol. 200, pp. 452-470, 2015.

[13] W. Wu, J. B. Zhu, and J. Zhao, "A further study on seismic response of a set of parallel rock fractures filled with viscoelastic materials," Geophysical Journal International, vol. 192, no. 2, pp. 671-675, 2013.

[14] Z.-H. Zhang, J.-H. Deng, and J.-B. Zhu, "A rapid and nondestructive method to determine normal and shear stiffness of a single rock joint based on 1d wave-propagation theory," Geophysics, vol. 83, no. 1, pp. WA89-WA100, 2018.

[15] J. C. Li, W. Wu, H. B. Li, J. B. Zhu, and J. Zhao, "A thin-layer interface model for wave propagation through filled rock joints," Journal of Applied Geophysics, vol. 91, pp. 31-38, 2013.

[16] L. F. Fan and L. N. Y. Wong, "Stress wave transmission across a filled joint with different loading/unloading behavior," International Journal of Rock Mechanics and Mining Sciences, vol. 60 , pp. 227-234, 2013.

[17] E. T. Brown and E. Hoek, "Trends in relationships between measured in-situ stresses and depth," International Journal of Rock Mechanics and Mining Science \& Geomechanics Abstracts, vol. 15, no. 4, pp. 211-215, 1978.

[18] F. V. Donzé, J. Bouchez, and S. A. Magnier, "Modeling fractures in rock blasting," International Journal of Rock Mechanics and Mining Sciences, vol. 34, no. 8, pp. 1153-1163, 1997.

[19] J. B. Zhu, Z. Y. Liao, and C. A. Tang, "Numerical SHPB tests of rocks under combined static and dynamic loading conditions with application to dynamic behavior of rocks under in situ stresses," Rock Mechanics and Rock Engineering, vol. 49, no. 10, pp. 3935-3946, 2016.

[20] M. Sagong, D. Park, J. Yoo, and J. S. Lee, "Experimental and numerical analyses of an opening in a jointed rock mass under biaxial compression," International Journal of Rock Mechanics and Mining Sciences, vol. 48, no. 7, pp. 1055-1067, 2011.

[21] L. X. Xie, W. B. Lu, Q. B. Zhang, Q. H. Jiang, G. H. Wang, and J. Zhao, "Damage evolution mechanisms of rock in deep tunnels induced by cut blasting," Tunnelling and Underground Space Technology, vol. 58, pp. 257-270, 2016.

[22] C. Yi, D. Johansson, and J. Greberg, "Effects of in-situ stresses on the fracturing of rock by blasting," Computers and Geotechnics, vol. 104, pp. 321-330, 2018.

[23] C. He, J. Yang, and Q. Yu, "Laboratory study on the dynamic response of rock under blast loading with active confining pressure," International Journal of Rock Mechanics and Mining Sciences, vol. 102, pp. 101-108, 2018. 
[24] J. J. Zhao, Y. Zhang, and P. G. Ranjith, "Numerical modelling of blast-induced fractures in coal masses under high in-situ stresses," Engineering Fracture Mechanics, vol. 225, Article ID 106749, 2019.

[25] X.-Q. Fang, T.-F. Zhang, B.-L. Li, and R.-J. Yuan, "Elastic-slip interface effect on dynamic stress around twin tunnels in soil medium subjected to blast waves," Computers and Geotechnics, vol. 119, Article ID 103301, 2020.

[26] J.-J. Zhao, Y. Zhang, and P. G. Ranjith, "Numerical simulation of blasting-induced fracture expansion in coal masses," International Journal of Rock Mechanics and Mining Sciences, vol. 100, pp. 28-39, 2017.

[27] Z.-L. Wang, Y.-C. Li, and R. F. Shen, "Numerical simulation of tensile damage and blast crater in brittle rock due to underground explosion," International Journal of Rock Mechanics and Mining Sciences, vol. 44, no. 5, pp. 730-738, 2007.

[28] G. W. Ma and X. M. An, "Numerical simulation of blastinginduced rock fractures," International Journal of Rock Mechanics and Mining Sciences, vol. 45, no. 6, pp. 966-975, 2008.

[29] Y. Gou, X. Shi, X. Qiu, J. Zhou, H. Chen, and X. Huo, "Propagation characteristics of blast-induced vibration in parallel jointed rock mass," International Journal of Geomechanics, vol. 19, no. 5, Article ID 04019025, 2019.

[30] Z. Zhu, B. Mohanty, and H. Xie, "Numerical investigation of blasting-induced crack initiation and propagation in rocks," International Journal of Rock Mechanics and Mining Sciences, vol. 44, no. 3, pp. 412-424, 2007.

[31] M. M. Dehghan Banadaki and B. Mohanty, "Numerical simulation of stress wave induced fractures in rock," International Journal of Impact Engineering, vol. 40-41, pp. 16-25, 2012.

[32] J. D. Chen, W. G. Yu, and S. Lu, "Performance analysis about high-power sparker source," Journal of Geophysical Equipment, vol. 23, pp. 165-168, 2013, (in Chinese).

[33] H. R. Nicholls and W. I. Duvall, "Pre-splitting rock in the presence of a static stress field," Technical Report, U.S. Dept. of the Interior, Bureau of Mines, Washington, DC, USA, 1966.

[34] K. R. Y. Simha and W. L. Fourney, "Studies on explosively driven cracks under confining in-situ stresses: in: rock mechanics in productivity and protection," in Proceedings of the 25th Symposium on Rock Mechanics, Evanston, IL, USA, June 1984.

[35] W. L. Fourney, R. D. Dick, X. J. Wang, and Y. Wei, "Fragmentation mechanism in crater blasting," International Journal of Rock Mechanics and Mining Science \& Geomechanics Abstracts, vol. 30, no. 4, pp. 413-429, 1993.

[36] S. Aziznejad, K. Esmaieli, J. Hadjigeorgiou, and D. Labrie, "Responses of jointed rock masses subjected to impact loading," Journal of Rock Mechanics and Geotechnical Engineering, vol. 10, no. 4, pp. 624-634, 2018.

[37] H. B. Li, X. Xiang, J. C. Li, J. Zhao, B. Liu, and Y. Q. Liu, "Rock damage control in bedrock blasting excavation for a nuclear power plant," International Journal of Rock Mechanics and Mining Sciences, vol. 48, pp. 210-218, 2011.

[38] P. Yan, W.-b. Lu, M. Chen, Y.-g. Hu, C.-b. Zhou, and $\mathrm{X}$.-x. Wu, "Contributions of in-situ stress transient redistribution to blasting excavation damage zone of deep tunnels," Rock Mechanics and Rock Engineering, vol. 48, no. 2, pp. 715-726, 2015.

[39] J. Yang, W. Lu, Y. Hu, M. Chen, and P. Yan, "Numerical simulation of rock mass damage evolution during deepburied tunnel excavation by drill and blast," Rock Mechanics and Rock Engineering, vol. 48, no. 5, pp. 2045-2059, 2015.
[40] LSTC, LS-DYNA Theoretical Manual, Livermore Software Technology Corporation, Livermore, CA, USA, 2010.

[41] M. Tao, X. Li, and C. Wu, "Characteristics of the unloading process of rocks under high initial stress," Computers and Geotechnics, vol. 45, pp. 83-92, 2012.

[42] S.-Y. Xiao, L.-J. Su, Y.-J. Jiang, and Z.-X. Liu, "Numerical analysis of hard rock blasting unloading effects in high in situ stress fields," Bulletin of Engineering Geology and the Environment, vol. 78, no. 2, pp. 867-875, 2017. 